\title{
Ion beam analysis of gas turbine blades: evaluation of refurbishment quality
}

\author{
O KAKUEE*，V FATHOLLAHI，P OLIAIY，D AGHA-ALIGOL and M LAMEHI-RACHTI \\ Physics and Accelerators Research School, NSTRI, PO Box 14395-836, Tehran, Iran
}

MS received 29 June 2013; revised 27 January 2014

\begin{abstract}
Refurbishment of hot components of gas turbines damaged in the harsh working environments is necessary to increase their lifetime. Scanning proton microscopy was employed to evaluate the quality of refurbishment process of gas turbine blades. Distribution patterns of different elements were observed in the polished cross-sections of turbine blade samples by proton microbeam. In the cross-sections of refurbished and used samples, distinct regions were identified corresponding to the base superalloy, original protection layer and applied coating for refurbishment. The elemental composition of each of these regions was measured by Micro-PIXE analysis. Inhomogeneous and high content of $\mathrm{Si}$ as well as undesired light elements were observed in the cross-sections of refurbished samples, indicating imperfections in the refurbishment process.
\end{abstract}

Keywords. Nuclear microprobe; Micro-PIXE; MCrAIY; thermal barrier coating; LPPS.

\section{Introduction}

Employment of gas turbine components in seriously harsh environments leads to their damage. ${ }^{1,2}$ These damages in the environment of hot combustion gases occur due to various processes, such as erosion, various types of corrosion, oxidation and also a complex combination of these damages. However, by applying a proper protective coating layer, surface damage of components in practice could be restricted.

Turbine blades investigated in this work employed in the first stage of a stationary power generator face temperatures from 800 to $1000^{\circ} \mathrm{C}$. This power generator normally consumes natural gas. However, during cold season, gas oil is used as the fuel of power station. The contaminants of the fuel as well as the base material and type of applied protective coating could play an important role in the erosion, corrosion and hence lifetime of the components employed in the gas turbine. The turbine blades are subjected to stress from centrifugal forces due to turbine stage rotation at about 3000 r.p.m. and fluid forces that can cause fracture, yielding or creep failures. ${ }^{3}$ The damaged turbine blades could be refurbished through a number of stages, including welding, brazing, coating and heat treatment in proper atmosphere.

Alloys or coatings resistant to oxidative environments at high temperatures rely on the formation of a dense and adherent surface oxide layer at the coating-environment interface. MCrAlY alloy ( $\mathrm{M}$ indicates $\mathrm{Ni}$, Co or a combination of the two metals), which is a resistive coating against oxidation, is commonly applied on the surface of turbine parts due to its rich content of $\mathrm{Cr}$ and $\mathrm{Al}^{4-6}$ In fact, high content of $\mathrm{Cr}$ and $\mathrm{Al}$ in this sacrificial coating leads to the

\footnotetext{
*Author for correspondence (okakuee@yahoo.com)
}

formation of physical barrier films of aluminium oxide and chromium oxide, which reduces the rate of high temperature attack to very low values. When these barrier films are lost due to spallation, erosion or other mechanisms, a new oxide film develops from the $\mathrm{Al}$ and $\mathrm{Cr}$ present in the MCrAlY coating. ${ }^{7}$ Consumption of $\mathrm{Cr}$ and $\mathrm{Al}$ continues until their content reaches below a minimum level for protection when the refurbishment process of the protective coating has to be implemented.

Low pressure plasma spray (LPPS) is a commercial technique for the production of MCrAlY protective coatings. It is a surface coating technique in which metallic and/or ceramic powders are injected into a high temperature and highspeed plasma jet, melted during flight, impinged on the substrate material, and solidified at a controlled atmosphere of 20-100 Torr. The prepared coatings by LPPS technique are of high density, high bonding strength with the substrate and mechanical durability. They are oxide free and could be thick coatings due to low thermal stresses. ${ }^{8,9}$ LPPS is commercially used in the refurbishment process of damaged gas turbine blades.

The aim of this study is to evaluate the refurbishment quality of used gas turbine blades by nuclear microprobe. For this purpose, elemental maps in the cross-sections of used and refurbished gas turbine blades were investigated and MicroPIXE analysis was carried out in the regions of interest. Particle-induced X-ray emission (PIXE) is a non-destructive well-established technique for trace element analysis. In this technique, multiple elements with high quantitative accuracy can be simultaneously measured with detection limits below $1 \mu \mathrm{g} \mathrm{g}^{-1}$ in some instances.

It should be noted that used and refurbished gas turbine blades with no sampling have already been investigated in 
a previous report by Kakuee et al. ${ }^{10}$ They showed that ion beam analysis could be exploited to determine whether it is the proper time for refurbishment of the gas turbine blade and also whether the spray parameters in the refurbishment process are suitably chosen.

\section{Experimental}

Investigated samples in this work collected from power generation industry, include two turbine blades corroded during operation in the power plant and two refurbished turbine blades by applying the MCrAlY thermal barrier protective coating using LPPS technique. Pieces of polished crosssections of the two refurbished blades (denoted by sample A and sample B) and those of the two used blades (denoted by sample $\mathrm{C}$ and sample D) were prepared for analysis by nuclear microprobe. It should be noted that sampling is performed from different parts of the investigated blades. Samples A and B are cut from the pressure side of the blades, while samples $\mathrm{C}$ and $\mathrm{D}$ are cut from the leading edge and suction side of the blades, respectively.

The samples were first mounted using moulding epoxy resins, and then were cut using cut-off machine. They were then pregrinded using sandpapers 100, 200, 320, 500, 600, 800,1200 and 2000 grit by employing mechanical grinding and polishing machine. In the next stage, the samples were polished using polishing clothes and diamond paste with grain size of $3 \mu \mathrm{m}$.

The analysing experiments of this research were performed using the 3MV Van de Graaff accelerator of Nuclear Science and Technology Research Institute (NSTRI). MicroPIXE analyses were carried out in the reaction chamber of a scanning proton microbeam system manufactured by Oxford Microbeam Ltd. The polished cross-sections of the samples were analysed using a $2.2 \mathrm{MeV}$ proton beam focused to a diameter of less than $10 \mu \mathrm{m}$. Characteristic X-rays of the samples were detected by a $\mathrm{Si}(\mathrm{Li})$ detector with an active area of $60 \mathrm{~mm}^{2}$ positioned at an angle of $135^{\circ}$ relative to the incident beam direction. The energy resolution of the $\mathrm{Si}(\mathrm{Li})$ detector was $150 \mathrm{eV}$ for $\mathrm{Fe}-\mathrm{K} \alpha$. The beam current was in the range of 30 to $80 \mathrm{pA}$. A maximum $2.5 \times 2.5 \mathrm{~mm}^{2}$ area of sample could be scanned by the proton beam. ADC signals from the detector were recorded event by event in list mode with the instantaneous beam position using the OM-DAQ data acquisition system. List mode files were replayed off-line and PIXE spectra of selected areas of the samples were generated. The collected X-ray spectra were then analysed using GUPIX ${ }^{11,12}$ software and elemental composition of each point of the sample was determined.

\section{Results and discussion}

Hot components of gas turbines when employed in aggressive service environments are prone to various environmental damages, such as wear caused by particles, different kinds of corrosion and oxidation and also a complex combination of these damages. Evaluating the amount of damage could assist one to determine the proper time for refurbishment of the turbine gas components using the protective layer coatings.

To evaluate the refurbishment quality of used gas turbine blades, scanning proton microscopy was employed to study the cross-sections of four samples of turbine blades denoted by $\mathrm{A}, \mathrm{B}, \mathrm{C}$ and $\mathrm{D}$. As region of interest is comparable to the microbeam scan size $\left(2.5 \times 2.5 \mathrm{~mm}^{2}\right)$, to analyse both the protective coating and the base superalloy, two regions of each sample were selected to be scanned by the nuclear microprobe.

Colour intensity in each microPIXE elemental distribution pattern indicates the concentration of corresponding element. Therefore, local difference in colour intensity could identify distinct regions of the sample. In our case, elemental distribution patterns of $\mathrm{Cr}$ in the refurbished samples $\mathrm{A}$ and $\mathrm{B}$ are shown in figure $1 \mathrm{a}$ and $\mathrm{b}$, while those in used samples $\mathrm{C}$ and $\mathrm{D}$ are shown in figure $1 \mathrm{c}$ and $\mathrm{d}$, respectively. Likewise, corresponding elemental distribution patterns of $\mathrm{Al}$ in the
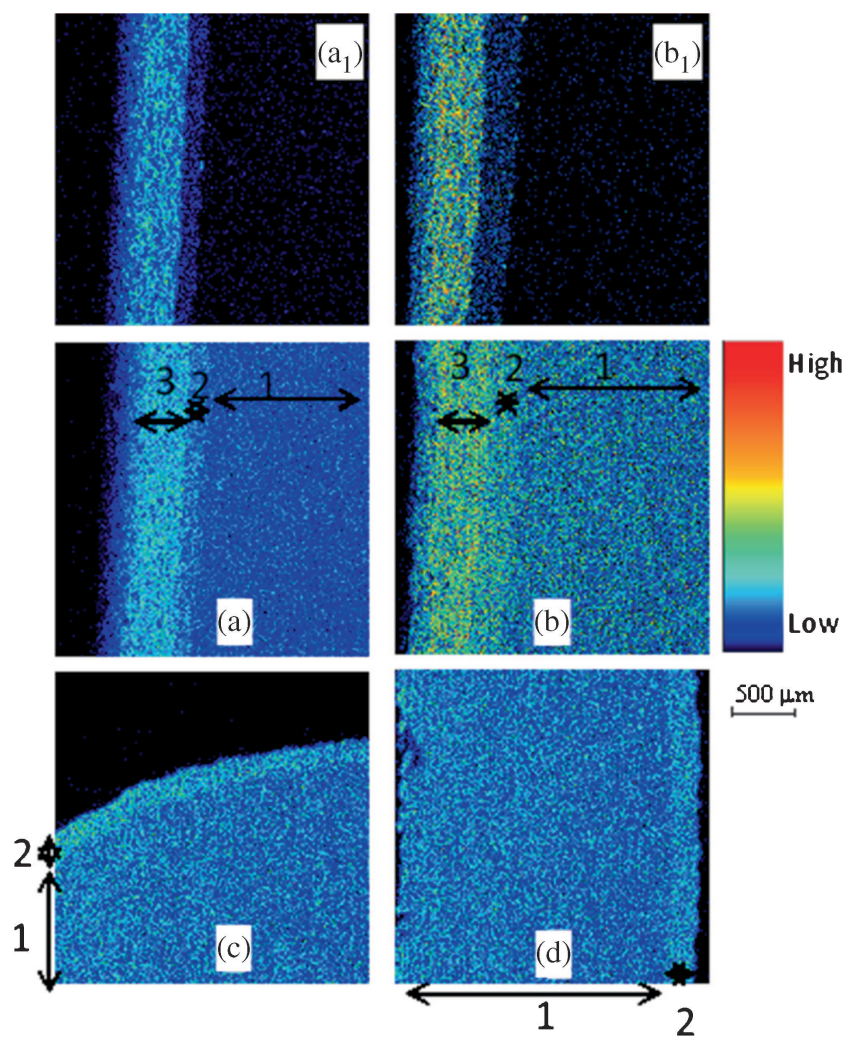

Figure 1. The distribution patterns of $\mathrm{Al}\left(\mathbf{a}_{1}\right.$ and $\left.\mathbf{b}_{1}\right)$ and $\mathrm{Cr}(\mathbf{a}-$ d) in the refurbished samples and in the used samples. ( $\mathbf{a}_{1}, \mathbf{b}_{1}, \mathbf{a}$ and b) Refurbished samples A and B in which three distinct regions of 1, 2 and 3 corresponding to base superalloy, original thermal barrier protective coating and MCrAlY coating layer are identified. (c and d) Used samples C and D in which two distinct regions of 1 and 2 corresponding to base superalloy and reminder of original thermal barrier protective coating are identified. 
samples $A$ and $B$ are shown in figure $1 a_{1}$ and $b_{1}$. As it can be seen in figure 1 , colour intensity due to different distribution patterns of $\mathrm{Cr}$ and $\mathrm{Al}$ in the four samples identifies three distinct regions in samples $\mathrm{A}$ and $\mathrm{B}$, and two distinct regions in samples $\mathrm{C}$ and $\mathrm{D}$. Three identified regions of 1, 2 and 3 correspond to base superalloy, original thermal barrier protective coating and MCrAlY coating layer applied by LPPS for refurbishment, respectively.

To be able to compare elemental distribution maps in different data sets, normalization factors for different data sets are determined based on the mean gray value of the base superalloy and are applied for the elemental distribution maps represented in this work.

In table 1 , the concentration of different elements in region 1 of samples A-D is shown. The concentration of elements in region 1 of the mentioned samples indicates that the turbine blades under investigation are likely made of nickel-base alloy Inconel with the approximate elemental concentration of $\mathrm{Ni}(>72 \%) \mathrm{Cr}(14 \%) \mathrm{Fe}(6 \%)$.

The concentrations of present elements in region 2 of the samples are shown in table 2. The weight percent of individual constituting elements of MCrAlY protective coating are measured by Micro-PIXE analysis to be $\mathrm{Co}(38 \%) \mathrm{Ni}(32 \%) \mathrm{Cr}(20 \%) \mathrm{Al}(8 \%) \mathrm{Y}(0.8 \%)$. It should be mentioned that small amounts of $\mathrm{Fe}$ and $\mathrm{Si}$ are also observed in some samples.

In table 3, the concentrations of present elements in region 3 of samples A and B are shown. The presence of high content of $\mathrm{Si}$ and undesired light elements, such as $\mathrm{Cl}, \mathrm{S}$, etc., in region 3 is of significance, as they could affect the performance of refurbished blades. ${ }^{7}$

Due to the presence of high concentration of $\mathrm{Ni}$ in the investigated samples, $\mathrm{Ni}\left(\mathrm{K}_{\alpha}\right)$ sum peak overlaps with $\mathrm{Y}\left(\mathrm{K}_{\alpha}\right)$ and hence the minimum detection limit (MDL) of PIXE for $\mathrm{Y}$ increases significantly. Therefore, $\mathrm{Y}$ concentration in MCrAlY coating of used and refurbished samples in tables 2 and 3 is only reported where the evaluated concentration of yttrium is higher than the MDL of PIXE.

Based on the data extracted from proton microbeam elemental maps and data of table 1 , it can be concluded that the base superalloy is made of Inconel 600 with a thickness of $2 \mathrm{~mm}$. Likewise, based on the data extracted from figure 1 and table 3 , it can be concluded that the refurbished coating layer is made of NiCoCrAlY with a thickness of about $0.5 \mathrm{~mm}$.

The intensity of $\mathrm{Cr}$ map in region 3 of figure 1a seems clearly higher than the other regions, but the $\mathrm{Cr}$ concentration data shown in tables 1-3 are not consistent with this map. To explain this conflict, one should note that matrix composition plays a prominent role in the analysis of data obtained by techniques based on characteristic X-rays. In fact, for interpretation of elemental distribution maps extracted by MicroPIXE analysis, due to high depth of proton penetration, attenuation of characteristic X-rays of different elements should be taken into account. With this in mind and according to the data represented in tables 1-3, presence of high amounts of low-Z elements in region 3 decreases the attenuation of $\mathrm{Cr}$ characteristic X-ray in the matrix in comparison with those in regions 1 and 2. Therefore, more $\mathrm{Cr}$ characteristic X-rays are detected by the detector in region 3 and hence in the $\mathrm{Cr}$ elemental map of this region, intensity of $\mathrm{Cr}$ is observed higher than the other regions. It should be noted that this conflict is corrected by GUPIX software in the determination of elemental composition.

In figure 2, Micro-PIXE spectra and corresponding GUPIX fits of three distinct regions of sample B are shown. These spectra could reveal the characteristic elements of each region and could inform the type and concentration of undesired elements. Moreover, in these spectra one could pay attention to the large amounts of $\mathrm{Si}$ in the refurbished coating layer as well as the presence of undesired light elements such as $\mathrm{P}, \mathrm{S}, \mathrm{Cl}, \mathrm{K}$ and $\mathrm{Ca}$.

Table 1. Elemental composition (in wt\%) of region 1 (corresponding to base superalloy) in the samples A-D.

\begin{tabular}{lcccccr}
\hline & Al & Si & Ti & Cr & Fe & \multicolumn{1}{c}{ Ni } \\
\hline Sample A & $0.44 \pm 0.06$ & $0.35 \pm 0.04$ & $0.21 \pm 0.02$ & $15.36 \pm 0.13$ & $9.23 \pm 0.13$ & $74.4 \pm 0.48$ \\
Sample B & $0.29 \pm 0.08$ & $0.23 \pm 0.05$ & $0.13 \pm 0.02$ & $15.94 \pm 0.16$ & $9.32 \pm 0.16$ & $74.08 \pm 0.59$ \\
Sample C & $0.33 \pm 0.06$ & $0.34 \pm 0.04$ & $0.18 \pm 0.01$ & $15.76 \pm 0.12$ & $9.12 \pm 0.12$ & $74.26 \pm 0.44$ \\
Sample D & - & - & $0.21 \pm 0.01$ & $15.98 \pm 0.12$ & $8.93 \pm 0.12$ & $74.88 \pm 0.45$ \\
\hline
\end{tabular}

Table 2. Elemental composition (in wt \%) of region 2 (corresponding to the original protective coating) in the samples A-D.

\begin{tabular}{lrrrrrrr}
\hline & Al & Si & Cr & Fe & Co & Ni & Y \\
\hline Sample A & $8.2 \pm 0.25$ & - & $20 \pm 0.21$ & $0.28 \pm 0.06$ & $37.7 \pm 0.49$ & $33.7 \pm 0.58$ & - \\
Sample B & $8.5 \pm 0.21$ & - & $20.3 \pm 0.19$ & - & $38.4 \pm 0.43$ & $32.8 \pm 0.50$ & - \\
Sample C & $10.6 \pm 0.20$ & $1 \pm 0.10$ & $19.6 \pm 0.16$ & $0.2 \pm 0.04$ & $36.2 \pm 0.35$ & $31.57 \pm 0.42$ & $0.84 \pm 0.10$ \\
Sample D & $8.79 \pm 0.20$ & $0.32 \pm 0.08$ & $20 \pm 0.16$ & $0.15 \pm 0.03$ & $38 \pm 0.38$ & $32.6 \pm 0.44$ & - \\
\hline
\end{tabular}




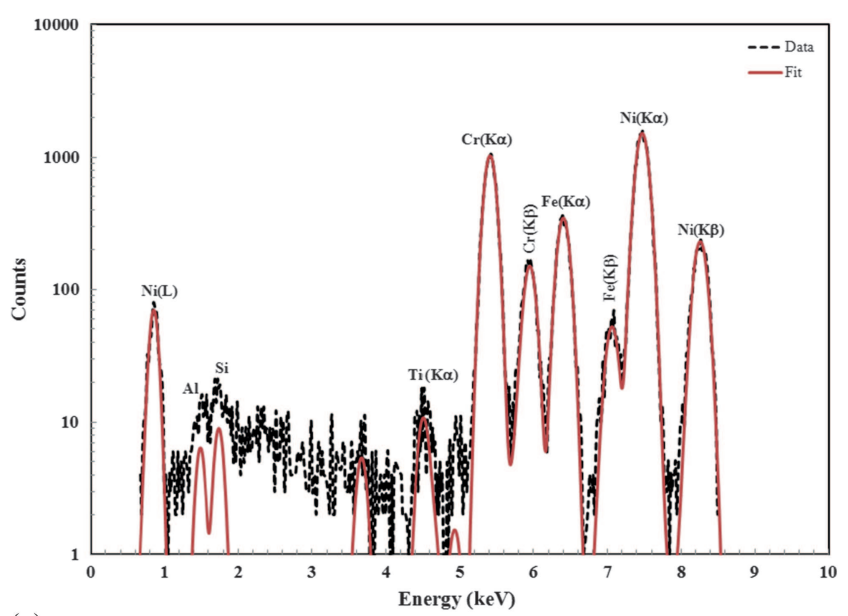

(a)

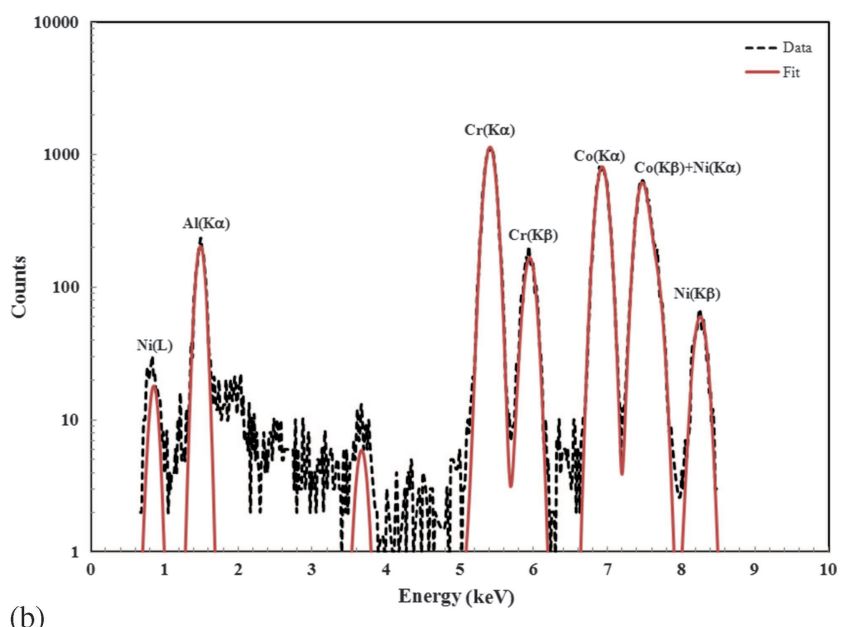

(b)

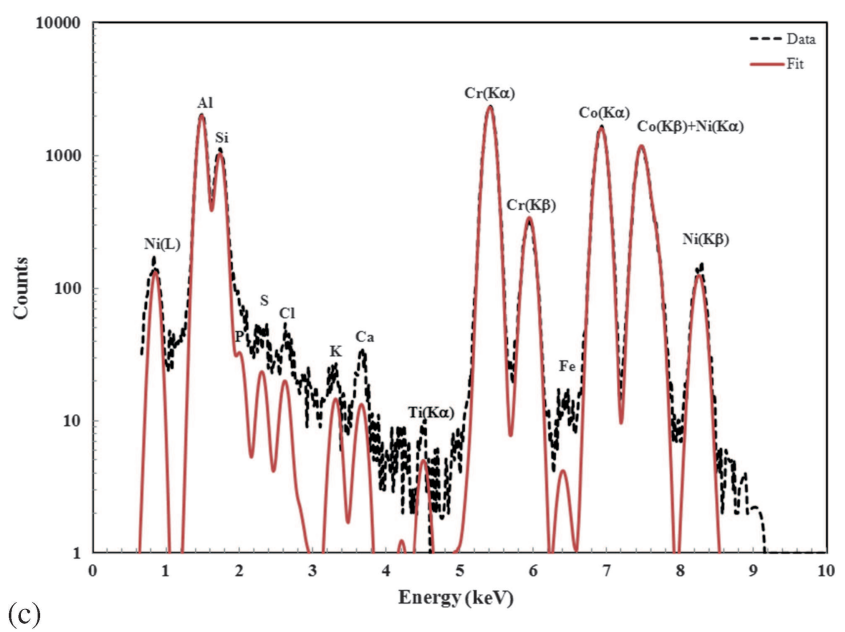

Figure 2. PIXE spectra and corresponding GUPIX fits of three distinct regions of refurbished sample $\mathrm{B}$ as identified in figure $1 \mathrm{~b}$. (a) Region 1, base superalloy; (b) region 2, original thermal barrier protective coating; (c) region 3, MCrAlY coating layer.

In figure 3, distribution patterns of $\mathrm{Si}$ and $\mathrm{Co}$ in sample $\mathrm{C}$ are shown. It should be noted that the data sets used for extraction of elemental distribution patterns in figures 1 and 3 are different and co-distribution map is just represented to 

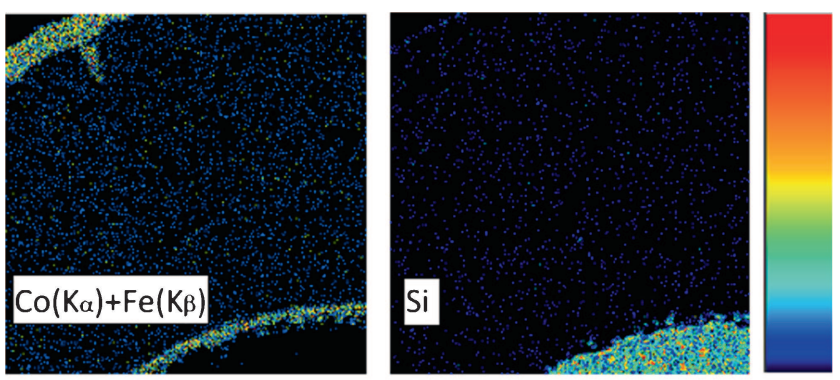

$500 \mu \mathrm{m}$

Figure 3. The distribution patterns of $\mathrm{Co}$ and $\mathrm{Si}$ in the used sample C.
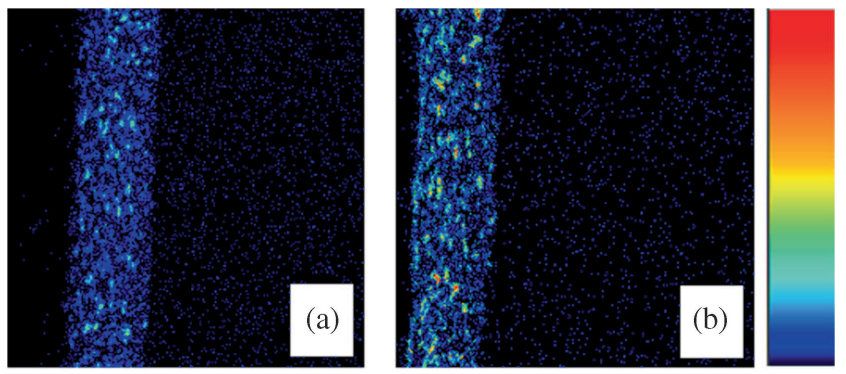

$\stackrel{500 \mu \mathrm{m}}{\longmapsto}$

Figure 4. (a and b) The distribution patterns of $\mathrm{Si}$ in the refurbished samples $\mathrm{A}$ and $\mathrm{B}$, respectively.

enable the reader to have an idea of the sample boundaries. As it is evident in this figure, $\mathrm{Si}$ is homogenously distributed in the base superalloy and protective coating layer as a trace element impurity. In fact, silicon dioxide $\left(\mathrm{SiO}_{2}\right)$ is found in most coatings along with other oxides as it is added to the powder during the manufacturing process to act as a deoxidizer and to modify the viscosity of the molten metal during the atomization manufacturing process. ${ }^{13}$

In figure 4, the distribution of $\mathrm{Si}$ in the refurbished samples A and B is shown. The inhomogeneity of Si distribution in the MCrAlY coating layer is clearly visible in this figure. This could lead to the degradation of refurbished coating protective layer. Obviously, scattered bulk distribution of $\mathrm{Si}$ in the coating, which is most likely due to sandblasting process prior to the application of protective coating, would negatively affect the adhesion of the coating to the underlying metal substrate as well as the lifetime of the protective coating layer.

In figure 5, the $\mathrm{Al}$ distribution map clearly identifies three distinct regions of MCrAlY refurbished coating layer, remainder of original thermal barrier coating and the base superalloy from left to right. In the lower part of this figure, depth profiles of $\mathrm{Si}, \mathrm{Al}, \mathrm{Cr}$ and undesired light elements of the same sample are correspondingly shown. These depth profiles, which reveal the distribution of light elements in the refurbished sample, are obtained by projecting map of each element on $X$-axis. In the lower part of the same figure, traces of light elements such as $\mathrm{P}, \mathrm{S}, \mathrm{Cl}, \mathrm{K}$ and $\mathrm{Ca}$ are observed in the whole depth of applied protective MCrAlY coating.

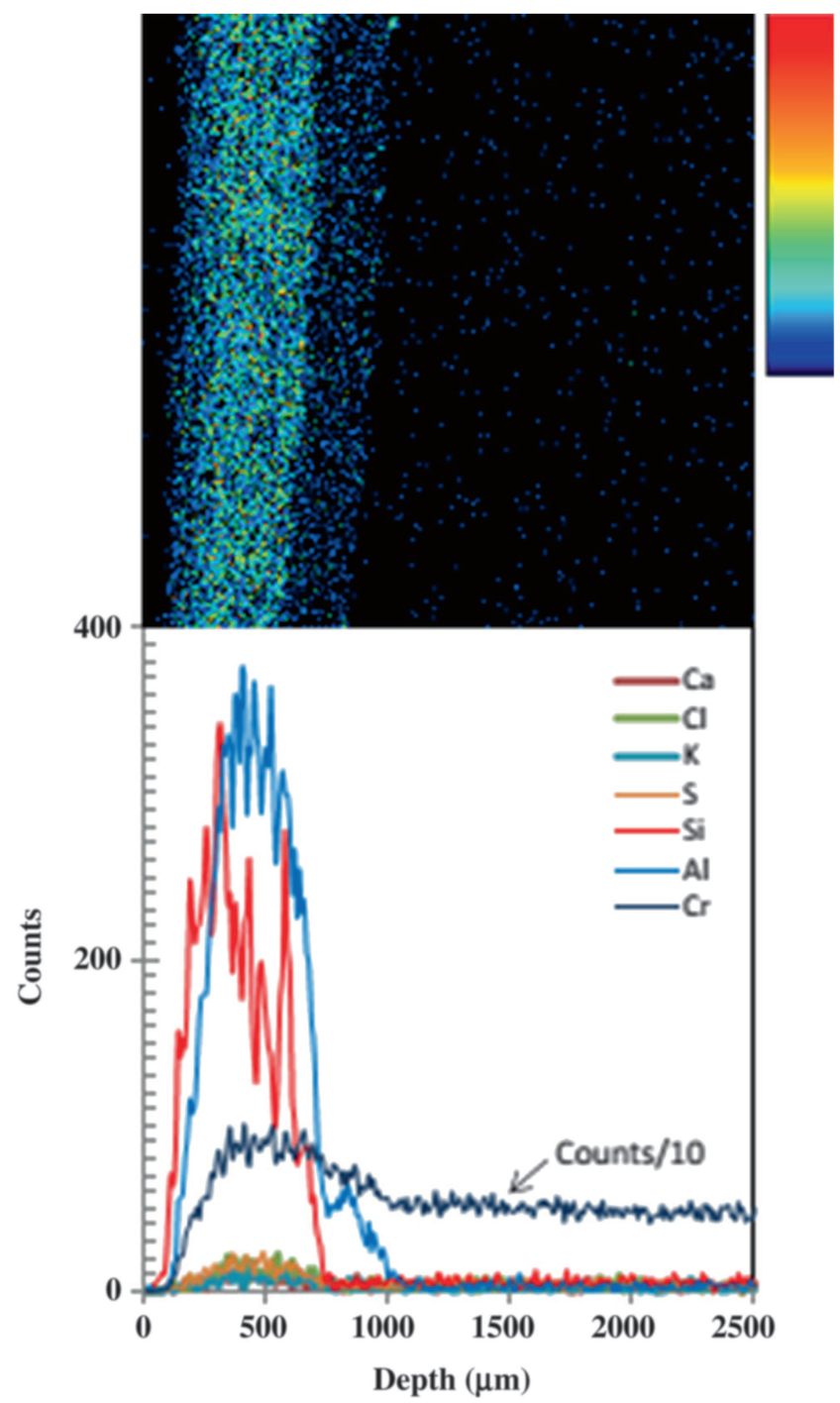

Figure 5. Up: the distribution pattern of $\mathrm{Al}$ in the refurbished sample A. Down: depth profiles of $\mathrm{Si}, \mathrm{Al}, \mathrm{Cr}$ and undesired light elements in the refurbished sample A. Note that the counts of $\mathrm{Cr}$ are divided by 10 to be shown in the same figure.

The presence of light elements in the refurbished coating could originate either from the processes performed during components preparation prior to deposition of the final protective layer such as sandblasting or from the sprayed source material. In fact, Takeda et $a l^{14}$ stated in their work that compositional change in sprayed materials was very small after LPPS deposition. Obviously, the presence of undesired light elements could negatively affect the bonding strength of the coating with the substrate, thermal conductivity and compactness of the coating. These imperfections could finally lead to higher corrosion rate and lower lifetime of the refurbished blades.

More interesting information could be extracted from the distribution pattern of elements obtained by scanning proton microscopy. For example, a hair crack in the base alloy of sample $\mathrm{C}$ could be observed in figure 6 . As it can be seen in this figure, the crack is completely filled with coating 

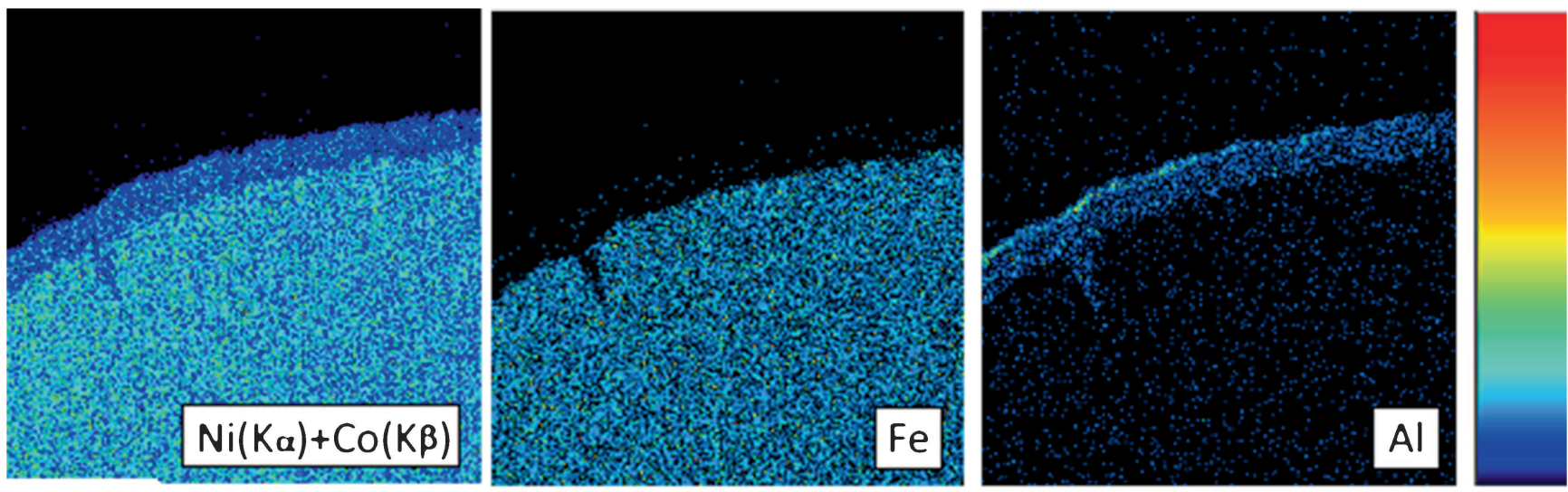

$500 \mu \mathrm{m}$

Figure 6. The distribution patterns of $\mathrm{Ni}, \mathrm{Fe}$ and $\mathrm{Al}$ in the base superalloy of used sample $\mathrm{C}$. The hair crack in the base alloy is clearly seen in the elemental distribution patterns.

alloy during the coating process. As the dimensions of the analysed region of the sample are known, the thickness of individual coating layers in different regions of the sample could be readily measured.

\section{Conclusion}

In this study, the distribution patterns of existing elements both in the matrix of base alloy and in the successive coatings of used and refurbished turbine blades were determined by scanning proton microscopy. The results of these analyses revealed the cluster distribution of rather large amounts of $\mathrm{Si}$ in the refurbished coating layer. The cluster distribution of $\mathrm{Si}$, which could reduce the lifetime of the component, is more likely due to the preparation of blades by sandblasting prior to the deposition of the final protective layer. However, the role of present impurities in the source material used for applying refurbished coating could not be ignored.

The presence of impurities such as light elements in the protective coating layers is a factor that could potentially reduce the mechanical strength and corrosion resistance of the coatings. In fact, observation of undesired light elements in the thermal barrier coating layer, irrespective of their origin, could indicate imperfections in the refurbishment process.

\section{Acknowledgement}

We would like to thank 'Shahriar Turbine Components Co.' for providing the turbine blade samples.

\section{References}

1. Pomeroy M J 2005 Mater. Design 26223

2. Wortman D J, Nagaraj B A and Duderstadt E C 1989 Mater. Sci. Eng. A 120-121 433

3. Walsh P P and Fletcher P 2004 Gas turbine performance, 2nd ed. (India, Blackwell Publishing)

4. Sreedhar G, Masroor Alam M D and Raja V S 2009 Surf. Coat. Technol. 204291

5. Gurrappa I and Sambasiva Rao A 2006 Surf. Coat. Technol. 2013016

6. Mercier D, Gauntt B D and Brochu M 2011 Surf. Coat. Technol. $\mathbf{2 0 5} 4162$

7. Stringer J 1998 Surf. Coat. Technol. 108-109 1

8. Willson R $200748^{\text {th }}$ AIAA/ASME/ASCE/AHS/ASC structural dynamics, and materials conference, Honolulu, Hawaii, AIAA

9. Wei Q, Yin Z and Li H 2012 Appl. Surf. Sci. 2585094

10. Kakuee O R, Fathollahi V, Agha-Aligol D, Farmahini-Farahani M, Oliaiy P and Lamehi-Rachti M 2008 Nucl. Instrum. Methods Phys. Res. Sect. B 2661132

11. Maxwell J A, Campbell J L and Teesdale W J 1989 Nucl. Instrum. Methods Phys. Res. Sect. B $\mathbf{4 3} 218$

12. Maxwell J A, Teesdale W J and Campbell J L 1995 Nucl. Instrum. Methods Phys. Res. Sect. B 95407

13. Trompetter W J, Markwitz A and Hyland M 2002 Nucl. Instrum. Methods Phys. Res. Sect. B 190518

14. Takeda K, Ito M and Takeuchi S 1990 Pure Appl. Chem. 62 1772 